\title{
A Role of Fluoride on Free Radical Generation and Oxidative Stress in BV-2 Microglia Cells
}

\author{
Xi Shuhua, Liu Ziyou, Yan Ling, Wang Fei, and Guifan Sun \\ Department of Environmental and Occupational Health, Liaoning Provincial Key Laboratory of Arsenic Biological Effect and Poisoning, \\ School of Public Health, China Medical University, District of Heping, North Er Road No. 92, Shenyang 110001, China
}

Correspondence should be addressed to Guifan Sun, sungf@mail.cmu.edu.cn

Received 8 May 2012; Revised 9 July 2012; Accepted 16 July 2012

Academic Editor: Dennis Daniel Taub

Copyright ( 92012 Xi Shuhua et al. This is an open access article distributed under the Creative Commons Attribution License, which permits unrestricted use, distribution, and reproduction in any medium, provided the original work is properly cited.

\begin{abstract}
The generation of ROS and lipid peroxidation has been considered to play an important role in the pathogenesis of chronic fluoride toxicity. In the present study, we observed that fluoride activated BV-2 microglia cell line by observing OX-42 expression in immunocytochemistry. Intracellular superoxide dismutase (SOD), glutathione (GSH), malondialdehyde (MDA), reactive oxygen species (ROS), superoxide anions $\left(\mathrm{O}_{2}{ }^{\circ-}\right)$, nitric oxide synthase (NOS), nitrotyrosine (NT) and nitric oxide (NO), NOS in cell medium were determined for oxidative stress assessment. Our study found that $\mathrm{NaF}$ of concentration from 5 to $20 \mathrm{mg} / \mathrm{L}$ can stimuli BV-2 cells to change into activated microglia displaying upregulated OX-42 expression. SOD activities significantly decreased in fluoride-treated BV-2 cells as compared with control, and MDA concentrations and contents of ROS and $\mathrm{O}_{2}{ }^{\cdot-}$ increased in NaFtreated cells. Activities of NOS in cells and medium significantly increased with fluoride concentrations in a dose-dependent manner. NT concentrations also increased significantly in 10 and $50 \mathrm{mg} / \mathrm{L} \mathrm{NaF-treated} \mathrm{cells} \mathrm{compared} \mathrm{with} \mathrm{the} \mathrm{control} \mathrm{cells.} \mathrm{Our}$ present study demonstrated that toxic effects of fluoride on the central nervous system possibly partly ascribed to activiting of microglia, which enhanced oxidative stress induced by ROS and reactive nitrogen species.
\end{abstract}

\section{Introduction}

Fluoride is an ubiquitous element in the environment and has a remarkable prophylactic effect at low concentrations by inhibiting dental caries, while at higher concentrations it causes dental and skeletal fluorosis [1]. Endemic fluorosis is prevalent in many parts of the world and causes damage not only to hard tissues of teeth and skeleton, but also to soft tissues, such as brain, liver, kidney, and spinal cord [2]. Epidemiological investigations reveal that intelligence quotient (IQ) of children living in endemic fluorosis areas is lower than that of children living in low fluoride areas [3-7]. It has been demonstrated that high concentrations of fluoride can decrease learning ability and memory in some animal experiments $[8,9]$ and result in dysfunctions of the central nervous system (CNS) $[10,11]$. As the cases of many chronic degenerative diseases, the increase of reactive oxygen species (ROS) and lipid peroxidation (LPO) has been considered to play an important role in the pathogenesis of chronic fluoride toxicity [12-14]. Fluoride administration significantly increases brain LPO level compared with control group in rat, while reduced glutathione (GSH) content and superoxide dismutase (SOD), glutathione peroxidase (GPx), and glutathione reductase (GR) activities decrease markedly in fluoride-treated groups $[15,16]$. There are significantly negative correlations between fluoride concentrations in brain and GPx activity, GSH level, and positive correlations between fluoride concentrations and thiobarbituric acid reactive substances (TBARSs) and carbonyl groups [17].

The CNS is especially sensitive to free radical oxidative damage as it contains more easily oxidizable fatty acids [18, 19]. ROS is produced during the respiratory burst of phagocytes, and the regulated generation of ROS plays an important role in host defense, oxygen sensing, and signal transduction $[20,21]$, while excessive production ROS promotes cellular injure and tissue damage. Macrophages are sources of free radicals, including ROS and reactive nitrogen species (RNS). Microglia are a kind of resident macrophage of the CNS and play a vital role in immune surveillance and injury repair [22,23]. Microglia activation is a common phenomenon in response to exposure to toxicants, and activated microglia are both phagocytic and potent sources 
of reactive oxygen and nitrogen intermediates [24-26]. Microglia excessive activation also can trigger or exacerbate neurotoxicity by inducing oxidative stress of neurons [27]. Nitric oxide (NO) production results from nitric oxide synthase (NOS) that catalyze the conversion of L-arginine to Lcitrulline and NO. At high concentrations, $\mathrm{NO}$ readily reacts with superoxide anion $\left(\mathrm{O}_{2}{ }^{--}\right)$, a kind of ROS derived from nicotinamide adenine dinucleotide phosphate (NADPH) oxidase (NOX), to produce peroxynitrite (ONOO). ONOO is able to irreversibly inhibit mitochondrial respiration, react with proteins, lipids, carbohydrates and DNA, and cause DNA fragmentation and lipid oxidation.

A growing number of studies have shown that fluoride can increase the generation of ROS and LPO in brain [15], but it is not known if ROS increasing in brain is related with activated microglia at fluoride exposure. In the present study, we treated BV-2 microglia cell line with different concentrations of fluoride and found that BV-2 microglia cells were activated. The levels of ROS and RNS were increased. The results indicated that activating BV-2 microglia cells by fluoride induced oxidative stress, which provides a potential oxidative stress mechanism for fluoride-related brain damage.

\section{Materials and Methods}

2.1. Chemicals and Reagents. Sodium fluoride (NaF, molecular weight 41.99) was procured from Sigma Chemical (St. Louis, MO, USA). All other analytical laboratory chemicals and reagents were obtained from Sigma, Invitrogen (Carlsbad, CA, USA), Hyclone (Logan, UT, USA).

2.2. Cell Culture and Treatment. The immortalized murine microglia cell line, BV-2, was provided by Cell Culture Center, School of Basic Medicine, Peking Union Medical College. The BV-2 cells were maintained in Dulbecco's modified Eagles medium (DMEM) that contained 10\% fetal bovine serum and antibiotics at $37^{\circ} \mathrm{C}$ in a $5 \% \mathrm{CO}_{2}$ humified incubator. Exponentially growing BV-2 cells at density of 5000 cells in $100 \mu \mathrm{L}$ medium were treated with $0.5-120 \mathrm{mg} / \mathrm{L}$ $\mathrm{NaF}$ respectively for 24,48 , and $72 \mathrm{~h}$ for cell viability assay. The concentrations of $\mathrm{NaF}(1,10$, and $50 \mathrm{mg} / \mathrm{L})$ were selected for intracellular SOD, GSH, malondialdehyde (MDA), ROS, $\mathrm{O}_{2}{ }^{\cdot-}$, NOS, Nitrotyrosine (NT) measurement and cell medium was collected for NO, NOS assay.

2.3. MTT Cell Viability Assay. Viability and growth patterns of BV-2 cells based on mitochondrial enzyme functions in 96-well plates were determined under NaF-treated for $24 \mathrm{~h}, 48 \mathrm{~h}$, and $72 \mathrm{~h}$ by 3-[4,5-dimethylthiazol-2-yl]-2,5diphenyltetrazolium bromide (MTT) conversion to formazan. Briefly, $100 \mu \mathrm{L}$ of MTT solution $(0.5 \mathrm{mg} / \mathrm{mL}$ in the medium) was added to each well, and the plates were incubated at $37^{\circ} \mathrm{C}$ for additional $4 \mathrm{~h}$. Afterwards, the medium containing MTT was removed, and the crystals were dissolved in $150 \mu \mathrm{L}$ of $100 \%$ dimethyl sulfoxide (DMSO). The cell viability was quantified using a microplate reader (Multiscan Ascent, Labsystems, Finland) at $570 \mathrm{~nm}$.
2.4. Immunocytochemistry. Following $\mathrm{NaF}$ treatment, cultured microglia were fixed with $4 \%$ paraformaldehyde and incubated with the diluted primary antibody $(1: 200$ OX-42, microglia marker) for $20 \mathrm{~min}$ at $37^{\circ} \mathrm{C}$, and secondary antibody sheep anti-mouse IgG was added for $20 \mathrm{~min}$ at $37^{\circ} \mathrm{C}$. After washing, the cells were incubated with $\mathrm{DAB}$ dilution until an observed color change. $100 \mathrm{ng} / \mathrm{mL}$ Lipopolysaccharides (LPS) was as a positive control. Staining of OX-42 was examined at high-power fields $(\times 400)$ under a standard light microscope. The number of cells as identified by OX42 antibody was counted in five different fields on each microscope slide.

\subsection{Determination of Intracellular GSH, SOD, and MDA.} BV-2 cells were cultured in $10 \mathrm{~cm}$ diameter dishes and treated with $\mathrm{NaF}$ as indicated. At the end of treatment, cells were washed 3 times with ice-cold phosphate-buffered saline (PBS), scraped off the dishes with a silicone "policeman" and harvested into Eppendorf tubes. Then cells were lyzed in PBS by sonication and centrifuged at $15000 \times \mathrm{g}$ for $5 \mathrm{~min}$ at $4^{\circ} \mathrm{C}$. The resulting supernatants were used immediately for the measurement. The intracellular GSH levels and SOD activity were measured with improved $5,5^{\prime}$-dithiobis(2-nitrobenzoic acid) (DTNB) method and hydroxylamine assay, respectively, provided by commercial test kits (KeyGen Biotech. Co. Ltd., Nanjing, China). The LPO was assessed by measuring MDA levels. The quantification was based on measuring formation of thiobarbituric acid reactive substances (TBARS) according to the manufacturer's protocol. Protein concentrations were determined by the method of Bradford [28] to normalize the levels of GSH, SOD, and MDA. The results were expressed as $\mathrm{mg} / \mathrm{g}$ protein for GSH, $\mathrm{U} / \mathrm{mg}$ protein for $\mathrm{SOD}$, and $\mathrm{nmoL} / \mathrm{mL}$ for MDA.

2.6. Measurement of Intracellular ROS and $\mathrm{O}_{2}{ }^{--}$Generation. The production of ROS was determined by measuring dichlorofluorescein (DCF) fluorescence as described by Rothe and Valet [29]. Briefly, BV-2 cells in 24-well culture plates, treated with $\mathrm{NaF}$ for $24 \mathrm{~h}$, were rinsed and resuspended in serum-free medium containing $10 \mu \mathrm{M}$ DCFH-DA. After a further $30 \mathrm{~min}$ of incubations at $37^{\circ} \mathrm{C}$, cells were rinsed twice with ice-cold PBS and harvested by trypsin, and were measured via a FACScan flow cytometer (Becton Dickinson, USA) with excitation wave length at $488 \mathrm{~nm}$ and emission wave length at $525 \mathrm{~nm}$ for ROS generation. The fluorescence intensity parallels to the amount of ROS formed. Intracellular $\mathrm{O}_{2}{ }^{-}$was detected by measuring dihydroethidium (DHE) fluorescence. Briefly, BV-2 cells were harvested after treated with $\mathrm{NaF}$ for $24 \mathrm{~h}$, washed with serum-free culture medium and incubated with $5 \mu \mathrm{M}$ DHE at $37^{\circ} \mathrm{C}$ for $30 \mathrm{~min}$. Then the cells were harvested, washed and resuspended, and were measured via a FACScan flow cytometer (BECTON DICKINSON, USA) with excitation wave length at $300 \mathrm{~nm}$ and emission wave length at $610 \mathrm{~nm}$ for $\mathrm{O}_{2}{ }^{--}$generation.

2.7. Determination of NO Release and NOS. BV-2 cells were treated with various concentrations of $\mathrm{NaF}$ for $24 \mathrm{~h}$. The 


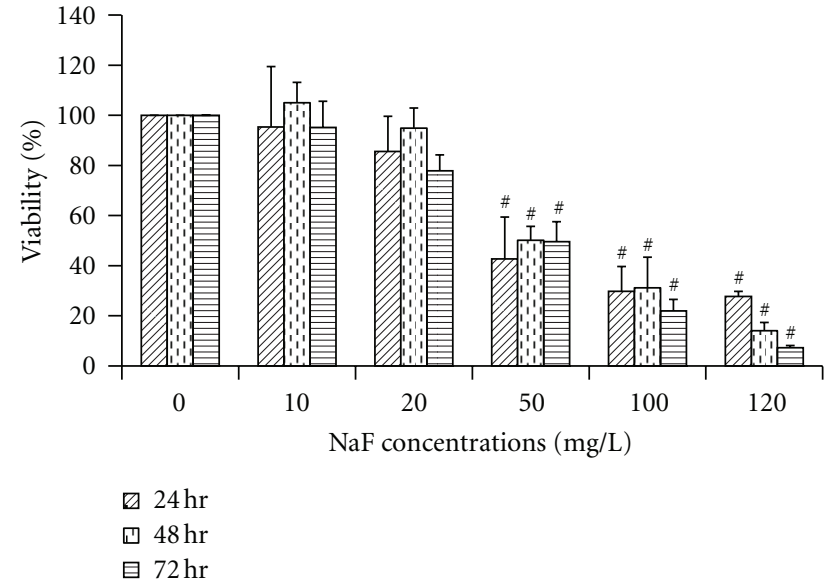

FIGURE 1: Effects of fluoride on cell viability in microglial BV-2 cells. Cells were treated with various concentrations of $\mathrm{NaF}$ and incubated for 24, 48, and $72 \mathrm{~h}$. Cell viabilities were measured using MTT assay, and data were presented as a percentage of the control. ${ }^{\#} P<0.01$ compared to the control group.

cell culture medium was collected, then centrifuged 1 min at $13000 \mathrm{rpm}$ to remove floating cells and cell debris, and analyzed immediately for nitrite content. The production of NO was determined by measurement the nitrite accumulation in the medium using colorimetric assay with Griess reagent. Nitrite concentrations were determined by comparison with standard solutions of sodium nitrite at optical density $550 \mathrm{~nm}$.

BV-2 cells and medium were collected after treated with $\mathrm{NaF}$ as indicated. Then cells were lyzed in PBS by sonication and centrifuged at $15000 \times \mathrm{g}$ for $5 \mathrm{~min}$ at $4^{\circ} \mathrm{C}$, the resulting supernatants and medium were used as sources of NOS, respectively. NOS activity was determined by monitoring the formation of [3H] L-citrulline from [3h] L-arginine as the method described previously [30]. The commercial test kit of NOS was provided by Nanjing Jiancheng Biological Corporation (Nanjing, China).

2.8. Enzyme-Linked Immunosorbent Assays (ELISA). BV-2 cells were treated with various concentrations of $\mathrm{NaF}$ for $24 \mathrm{~h}$, and the intracellular NT was assessed by ELISA using monoclonal antibodies and the procedure recommended by the supplier (Abway Antibody Technology Co., Ltd., Beijing, China). The concentration of NT was calculated according to the standard curve of the ELISA kits.

2.9. Statistical Analysis. All experiments were performed at least in triplicate and the values represent mean \pm SD. Differences between groups were statistically analyzed by one-way analysis of variance (ANOVA) and positive rates of OX-42 expression were analyzed by the Fisher Exact test. Differences between experimental groups with a $P$ value $<0.05$ were considered significant.

\section{Results}

3.1. Fluoride Decreased the Cell Viability of BV-2 Cells. As shown in Figure 1, fluoride reduced the BV-2 cell viability in 50,100 , or $120 \mathrm{mg} / \mathrm{L} \mathrm{NaF}$ groups. At concentrations of 50,100 , or $120 \mathrm{mg} / \mathrm{L}$, sodium fluoride caused a significant decrease in cell viability of $57 \%, 70 \%$, and $72 \%$, respectively, versus control at NaF-treated $24 \mathrm{~h}, 50 \%, 69 \%$, and $86 \%$, respectively, versus control at NaF-treated $48 \mathrm{~h}$, and $51 \%$, $78 \%$, and $92 \%$, respectively, versus control at NaF-treated $72 \mathrm{~h}$.

3.2. BV-2 Cell Activation after Treatment with Fluoride. Integrin $\alpha \mathrm{M}(\mathrm{OX}-42)$ is a cell adhesion molecule that acts as a receptor for cell surface ligands. Immunocytochemistry localization with an OX-42 antibody was used as a microglial marker. To confirm the activation of BV-2 in response to $\mathrm{NaF}$, OX-42 expression was determined by immunocytochemistry after $24 \mathrm{~h}$ incubation with different $\mathrm{NaF}$ concentrations (1$20 \mathrm{mg} / \mathrm{L}$ ). $\mathrm{NaF}$ of concentrations from 5 to $20 \mathrm{mg} / \mathrm{L}$ can stimulate $\mathrm{BV}-2$ cells to change into activated microglia displaying upregulated OX-42 expression and large bodies compared with control microglia with small bodies and long branch (Figure 2). The number of cells showing OX-42 positive expression markedly increased in 5, 10, and $20 \mathrm{mg} / \mathrm{L}$ NaF-treated BV-2 cells compared with the control.

3.3. Effects on the Levels of SOD, GSH, MDA, and ROS of Fluoride in BV-2 Cells. As shown in Figure 3, a marked decrease in SOD activities was observed in fluoride-treated BV-2 cells. SOD activities decreased significantly by $22.3 \%$, $25.6 \%$, and $34.4 \%$ in 1,10 , and $50 \mathrm{mg} / \mathrm{L} \mathrm{NaF}$-treated cells, respectively, compared to the control cells, and there was a significant negative dose-effect relationship $(r=0.804, P<$ 0.01 ). The content of intracellular ROS was evaluated by the changes in DCF fluorescence intensity. DCF fluorescence intensities in BV-2 cells increased with fluoride concentrations, with a significant dose-dependent manner $(r=0.851$, $P<0.01)$, and the DCF fluorescence intensities in the $50 \mathrm{mg} / \mathrm{L}$ NaF-treated cells were significantly higher than the control cells $(P<0.01)$. MDA concentrations also increased in NaF-treated cells, and there was a significant positive dose-effect relationship $(r=0.5, P<0.05)$ although there were no statistical differences in NaF-treated cells compared with the control cells. However, there was an increase tendency in NaF-treated cells compared to the control for the intracellular GSH levels.

3.4. Effects on NOS Activity and NO Concentration of Fluoride in BV-2 Cells. In addition to ROS, RNS from activated microglia can be a major cause of oxidative stress. We therefore measured $\mathrm{NO}$ and NOS in BV-2 cells treated with various concentrations of fluoride for $24 \mathrm{~h}$. NO level in the culture medium did not increase with fluoride concentrations. However, activities of NOS, synthesizing NO, significantly increased in 1, 10, and $50 \mathrm{mg} / \mathrm{L} \mathrm{NaF-treated} \mathrm{BV-2} \mathrm{cell} \mathrm{culture}$ medium compared with the control, in a dose-dependent manner $(r=0.96, P<0.01)$. Intracellular NOS activities only increased in $10 \mathrm{mg} / \mathrm{L} \mathrm{NaF-treated} \mathrm{BV-2} \mathrm{cells} \mathrm{compared}$ with the control, see Figure 4.

3.5. The $\mathrm{O}_{2}{ }^{--}$and NT Level in NaF-Treated BV-2 Cells. The content of intracellular $\mathrm{O}_{2}{ }^{\bullet-}$ was determined by the changes 


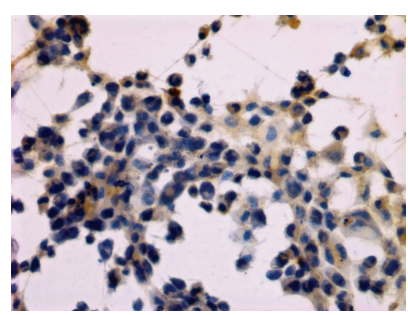

(a)

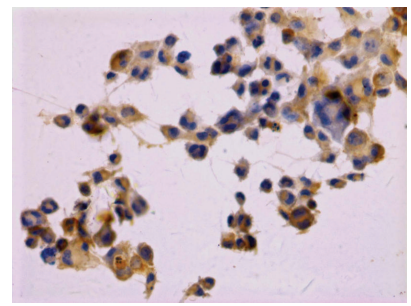

(d)

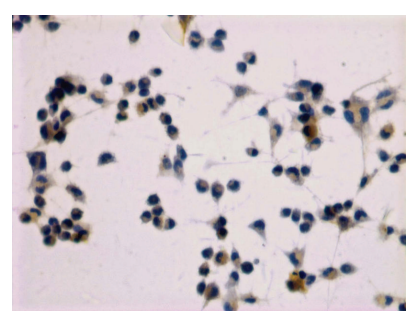

(b)

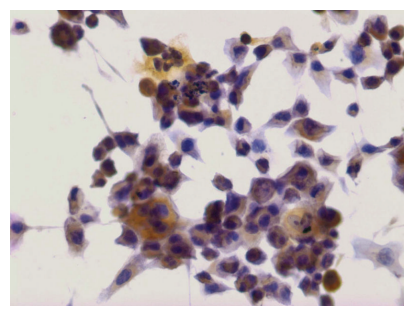

(e)

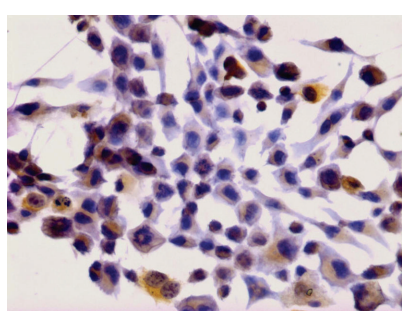

(c)

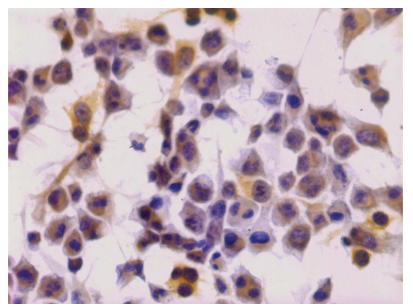

(f)

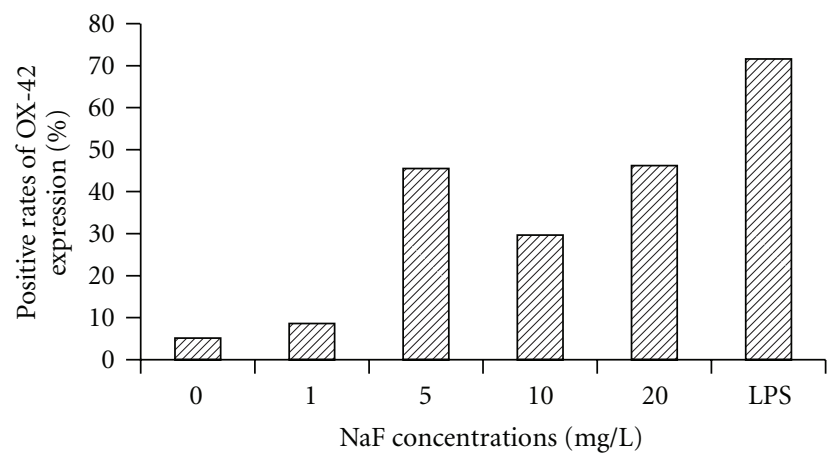

FIGURE 2: The activity of microglial BV-2 cells induced by fluoride. Cells were treated with indicated concentrations of NaF for $24 \mathrm{~h}$ and immunocytochemistry localization with an OX-42 antibody as a microglial marker were observed. Microglial activity was detected by OX42 expression, and the microglia cells treated with LPS were used as a positive control. Morphological changes of microglia from the resting state ((a) small cell bodies and thin, long, or ramified processes) to the activated state ((c), (d), (e), (f) larger cell bodies with short, thick) were observed after fluoride or LPS treatment in the BV-2 cells. High expression areas of OX-42 immunoreactivity were indicated by arrows. Optic microscopy: HE (400×). (a) control, (b) $1 \mathrm{mg} / \mathrm{L} \mathrm{NaF,} \mathrm{(c)} 5 \mathrm{mg} / \mathrm{L} \mathrm{NaF}$, (d) $10 \mathrm{mg} / \mathrm{L} \mathrm{NaF}$, (e) $20 \mathrm{mg} / \mathrm{L} \mathrm{NaF,} \mathrm{and} \mathrm{(f)} 100 \mathrm{ng} / \mathrm{mL} \mathrm{LPS}$.

in DHE fluorescence intensity. DHE fluorescence intensities in BV-2 cells increased with fluoride concentrations, with a significant dose-dependent manner $(r=0.943, P<$ 0.01 ), and the DHE fluorescence intensities in the 1,10, and $50 \mathrm{mg} / \mathrm{L} \mathrm{NaF}$-treated cells were significantly higher than the control cells. Peroxynitrite, the reaction product of NO and $\mathrm{O}_{2}{ }^{--}$, can lead to macromolecule damage and formation of NT, a protein adduct, and NT has been as a marker of free radical oxidation of nitric oxide. Our study showed that intracellular NT concentrations in BV-2 cells increased significantly following fluoride exposure in 10 and $50 \mathrm{mg} / \mathrm{L}$ NaF-treated groups compared with the control group, and there also existed a dose-dependent enhancement $(r=0.603$, $P<0.05)$, see Figure 5.

\section{Discussion}

The redox balance of the cell maintained by oxidants and antioxidants is important to physiological activity and function. Disturbance of the natural equilibrium of free radical over generation causes dysfunction and promotes oxidative damage to tissue. Although ROS have some essential roles in normal cell functions [31], they are more associated with their pathological effects that ultimately lead to protein and cellular damage as well as cell death $[32,33]$. ROS could attack numerous cell components like membrane lipids, resulting in enhanced lipid peroxidation and cellular toxicity. ROS has been related with the pathologies of over one hundred diseases. Many studies [34, 35] have reported that excessive fluoride exposure can damage the redox balance of the cells in tissues, decrease antioxidant defense capacity in brain [15], and increase the toxic effects on visceral organs mediated by generation of ROS and lipid peroxidation [36]. A close association between chronic fluoride toxicity and increased oxidative stress has been reported in humans and in experimental animals $[37,38]$. Neurotoxicity induced by fluoride had been linked with oxidative stress $[11,16]$.

Microglia are the resident immune cells in the brain and readily activated by a variety of foreign substances 


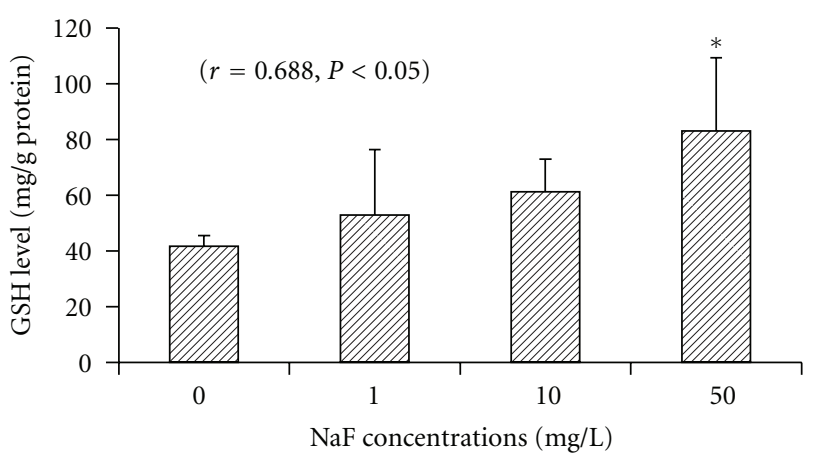

(a)

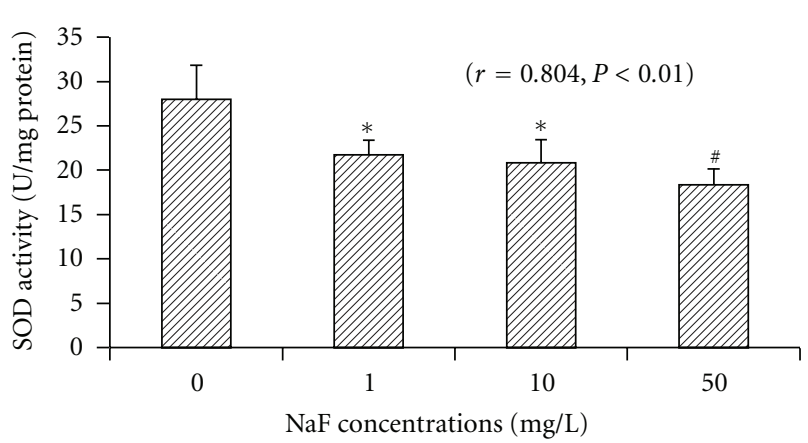

(b)

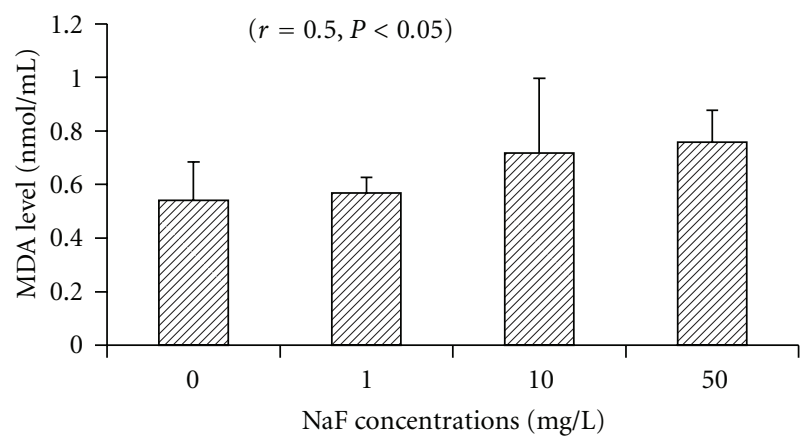

(c)

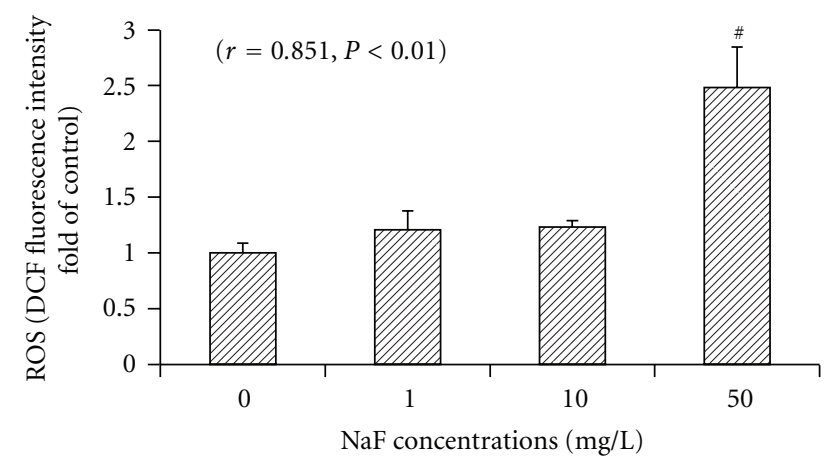

(d)

Figure 3: Effects of fluoride on intracellular GSH levels (a); SOD activity (b); LPO production (MDA) (c) and ROS production (d) in microglial BV-2 cells. After the cells were treated with various concentrations of $\mathrm{NaF}(1,10$, and $50 \mathrm{mg} / \mathrm{L})$ for $24 \mathrm{~h}$, the contents of GSH, MDA and the activities of SOD were measured using commercial test kits. DCF fluorescence intensity was measured by flow cytometry for ROS content and DCF fluorescence intensity fold of control was analyzed. Bars were presented as mean \pm SD. ${ }^{*} P<0.05$ and ${ }^{\#} P<0.01$ compared to the control group.

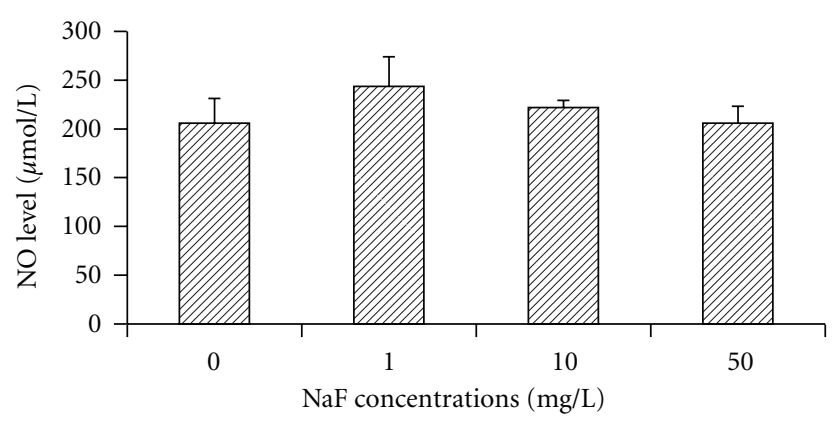

(a)

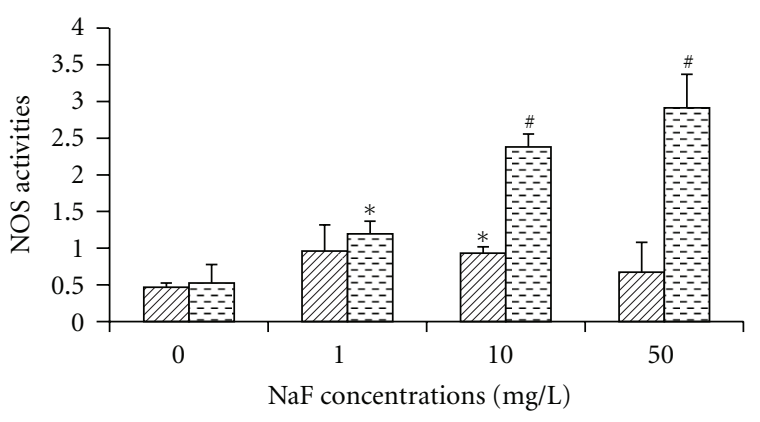

च NOS in supernatants (U/mg protein) $\square$ NOS in medium $(\mathrm{U} / \mathrm{mL})$

(b)

FIgure 4: Effects of fluoride on NO production (a), and NOS activities (b) in microglial BV-2 cells. After the cells were treated with various concentrations of $\operatorname{NaF}(1,10$, and $50 \mathrm{mg} / \mathrm{L})$ for $24 \mathrm{~h}$, NO release in culture medium and NOS activities in supernatants and medium were measured using commercial test kits. Bars were presented as mean \pm SD. ${ }^{*} P<0.05$ and ${ }^{\#} P<0.01$ compared to the control group.

including environmental toxicants [39]. The beneficial roles of microglia activation include clearance of toxic cell debris and pathogens, induction of innate immune responses, and enhancement of neuronal survival. However, an array of ROS and RNS produced and secreted from activated microglia has been believed to be involved with neurotoxicity in brain disorders [40-42]. In the present study, we also observed that ROS increased in fluoride-treated microglia BV-2 cells. Several in vivo studies have reported microglial proliferation and activation early after various brain insults [43]. Thus, it can be hypothesized that oxidative stress of microglia could be one of the causative factors for fluoride induced brain toxicity. Once activated, microglia undergo morphological changes as well as phenotypic alterations in some molecules. Microglial activation is generally measured by a gradual change in morphology from a quiescent ramified form (resting state) to an amoeboid form (activated state) [44], and upregulation of cell surface receptors, such as CD11b (OX-42) [45]. In this study, the majority of NaF-treated BV-2 microglial cells displayed an activated morphology and increased the expression of OX-42 receptor, an abundance surface receptor in activated microglia. The increased number of OX-42 microglia observed in this study may be due to the reactive response of microglia to fluoride 


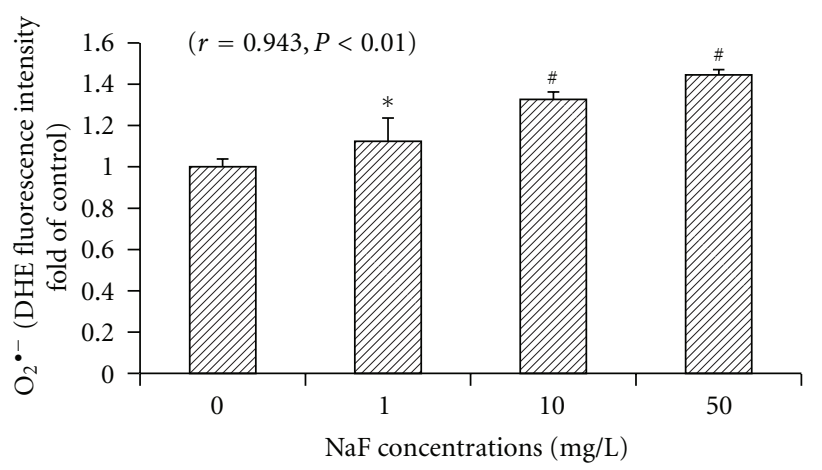

(a)

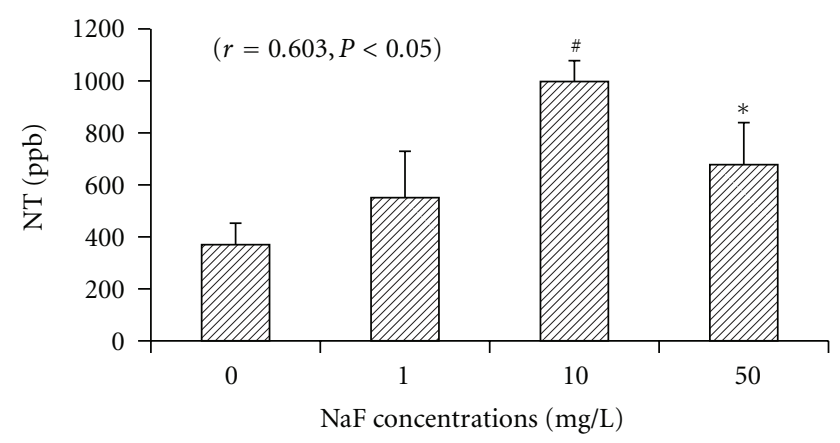

(b)

Figure 5: Effects of fluoride on $\mathrm{O}_{2}{ }^{--}$production (a) and NT concentrations (b) in microglial BV-2 cells. BV-2cells were treated with various concentrations of $\mathrm{NaF}(1,10$, and $50 \mathrm{mg} / \mathrm{L})$ for a $24 \mathrm{~h}$ incubation period, and DHE fluorescence intensity was measured by flow cytometry for $\mathrm{O}_{2}{ }^{--}$content and DHE fluorescence intensity fold of control was analyzed. Intracellular NT concentrations were measured by ELISA. Bars were presented as mean \pm SD. ${ }^{*} P<0.05$ and ${ }^{\#} P<0.01$ compared to the control group.

treatment. To our knowledge, this is the first time to verify that microglia are activated by fluoride.

The characteristic features of microglial activation are NOX activation and oxidative burst activity increasing. NOX is a superoxide producing enzyme system, the major source of ROS in microglia [46-48]. Superoxide anions $\left(\mathrm{O}_{2}{ }^{--}\right)$ derivated from NOX can be catalyzed into the hydrogen peroxide $\left(\mathrm{H}_{2} \mathrm{O}_{2}\right)$ and molecular oxygen by SOD. SOD accelerates $\mathrm{O}_{2}{ }^{--}$to $\mathrm{H}_{2} \mathrm{O}_{2}$, which can be said as primary defence, as it prevents further generation of free radicals. In the present study, the SOD activity significantly decreased in dose-dependent manner and $\mathrm{O}_{2}{ }^{\bullet-}$ content increased in fluoride-treated $\mathrm{BV}-2$ microglia. It can be explained that $\mathrm{O}_{2}{ }^{--}$generation consumed SOD. Superoxide radicals especially cause oxidation of - $\mathrm{SH}$ groups in protein, and it has been demonstrated that thiolate radicals are removed by GSH [49]. GSH also participates in the reaction that destroys hydrogen peroxide, or organic peroxide, free radicals, and certain foreign compounds. GSH is as a direct free radical scavenger, as a cosubstrate for GPx activity and as a cofactor for many enzymes and forms conjugates in endo- and xeno-biotic reactions [50]. The decrease in GSH level is often observed due to increased utilization in oxidative stress. In contrast, GSH levels in BV-2 microglial cells increased with fluoride concentrations in our present study. Oxidative stress is defined as a disturbance in the balance between the production of free radicals and antioxidant defense, and the later is more compensatory [14]. Our observed increase of GSH may be a compensation increase to scavenge excessive superoxides and protect cells against oxidative stress. This may be part of the general physiological response of the body to ROS.

The production of lipid peroxidation, such as MDA, was accumulated as a result of membrane disruption, elicited by the oxidation of poly unsaturated fatty acids of the bilayer. The present study found that the MDA levels showed an increasing tendency in NaF-treated BV-2 cells although there were no significant differences between NaF-treated BV2 cells and control cells. However, ROS level in $50 \mathrm{mg} / \mathrm{L}$ NaF-treated group increased significantly, which indicated that ROS could attack membrane lipids and result in lipid peroxidation.

$\mathrm{NO}$ is a compound of special interest released by activated microglia and has been described in vitro situations to be an important mechanism by which microglia cause neuronal death [51-53]. NO is produced from L-arginine and molecular oxygen by the action of NOS $[54,55]$ in activated microglia and contribute to the oxidative stress accompanying the inflammatory process [56]. NOS is the key enzyme for NO production and is quantitatively induced in activated glial cells after exposure to stimulators. The neurotoxic effects of $\mathrm{NO}$ are generally attributed to its reaction with $\mathrm{O}_{2}{ }^{--}$to form $\mathrm{ONOO}^{-}$, an extremely active oxidizing agent, which can lead to macromolecule damage and form the protein adduct, such as NT, and NT has been as a marker of free radical oxidation of nitric oxide. In the present study, fluoride significantly increased the NOS activity in activated BV-2 cells, and which should produce more NO. Interestingly, in our experiment, NO level did not increase after BV-2 cells were exposed to fluoride, that could due to produced $\mathrm{NO}$ reacted rapidly with $\mathrm{O}_{2}{ }^{--}$to form $\mathrm{ONOO}^{-}$. Indeed, we have observed a significant increase of NT level at 10 and $50 \mathrm{mg} / \mathrm{L} \mathrm{NaF-treated} \mathrm{cells,} \mathrm{suggesting} \mathrm{that}$ neurotoxicity of fluoride is associated with overproduction of nitric oxide and peroxynitrite. Therefore, RNS, together with ROS produced by activated microglia was involved in oxidative stress induced by fluoride in activated BV-2 cells.

In conclusion, a main finding of this study was that microglia BV-2 cells were activated by fluoride, and the increase of ROS and RNS in microglia was associated with the activation of microglia. The novelty of this work is related to the active role of microglia treated with fluoride. We provided new evidence from in vitro model indicating that fluoride exerts its toxic effects in CNS possibly partly ascribed to activating of microglia in vitro, which enhanced oxidative stress induced by ROS and RNS. Of course, the detailed effect and mechanism need further investigation in vivo.

\section{Acknowledgment}

This study was supported by the Ministry of Education, Science and Technology Development Center of China, Grant no. 20112104110021. 


\section{References}

[1] D. Chachra, A. P. G. F. Vieira, and M. D. Grynpas, "Fluoride and mineralized tissues," Critical Reviews in Biomedical Engineering, vol. 36, no. 2-3, pp. 183-223, 2008.

[2] D. L. Ozsvath, "Fluoride and environmental health: a review," Reviews in Environmental Science and Biotechnology, vol. 8, no. 1, pp. 59-79, 2009.

[3] Y. Lu, Z. R. Sun, L. N. Wu, X. Wang, W. Lu, and S. S. Liu, "Effect of high-fluoride water on intelligence in children," Fluoride, vol. 33, no. 2, pp. 74-78, 2000.

[4] L. B. Zhao, G. H. Liang, D. N. Zhang, and X. R. Wu, "Effect of a high fluoride water supply on children's intelligence," Fluoride, vol. 29, no. 4, pp. 190-192, 1996.

[5] X. S. Li, J. L. Zhi, and R. O. Gao, "Effect of fluoride exposure on intelligence in children," Fluoride, vol. 28, no. 4, pp. 189-192, 1995.

[6] Q. Xiang, Y. Liang, L. Chen et al., "Effect of fluoride in drinking water on children's intelligence," Fluoride, vol. 36, no. 2, pp. 84-94, 2003.

[7] S. X. Wang, Z. H. Wang, X. T. Cheng et al., "Arsenic and fluoride expose in drinking water: children's IQ and growth in Shanyin Country, Shanxi Province, China," Environmental Health Perspectives, vol. 115, no. 4, pp. 643-647, 2007.

[8] R. Niu, Z. Sun, J. Wang, Z. Cheng, and J. Wang, "Effects of fluoride and lead on locomotor behavior and expression of nissl body in brain of adult rats," Fluoride, vol. 41, no. 4, pp. 276-282, 2008.

[9] L. R. Chioca, I. M. Raupp, C. Da Cunha, E. M. Losso, and R. Andreatini, "Subchronic fluoride intake induces impairment in habituation and active avoidance tasks in rats," European Journal of Pharmacology, vol. 579, no. 1-3, pp. 196-201, 2008.

[10] M. Bhatnagar, P. Rao, S. Jain, and R. Bhatnagar, "Neurotoxicity of fluoride: neurodegeneration in hippocampus of female mice," Indian Journal of Experimental Biology, vol. 40, no. 5, pp. 546-554, 2002.

[11] P. J. Mullenix, P. K. Denbesten, A. Schunior, and W. J. Kernan, "Neurotoxicity of sodium fluoride in rats," Neurotoxicology and Teratology, vol. 17, no. 2, pp. 169-177, 1995.

[12] K. R. Shan, X. L. Qi, Y. G. Long, A. Nordberg, and Z. Z. Guan, "Decreased nicotinic receptors in PC12 cells and rat brains influenced by fluoride toxicity-a mechanism relating to a damage at the level in post-transcription of the receptor genes," Toxicology, vol. 200, no. 2-3, pp. 169-177, 2004.

[13] I. Inkielewicz and W. Czarnowskia, "Oxidative stress parameters in rats exposed to fluoride and aspirin," Fluoride, vol. 41, no. 1, pp. 76-82, 2008.

[14] Q. Gao, Y. J. Liu, and Z. Z. Guan, "Oxidative stress might be a mechanism connected with the decreased $\alpha 7$ nicotinic receptor influenced by high-concentration of fluoride in $\mathrm{SH}$ SY5Y neuroblastoma cells," Toxicology in Vitro, vol. 22, no. 4, pp. 837-843, 2008.

[15] V. K. Bharti and R. S. Srivastava, "Fluoride-induced oxidative stress in rat's brain and its amelioration by buffalo (Bubalus bubalis) pineal proteins and melatonin," Biological Trace Element Research, vol. 130, no. 2, pp. 131-140, 2009.

[16] P. M. Basha and N. Madhusudhan, "Pre and post natal exposure of fluoride induced oxidative macromolecular alterations in developing central nervous system of rat and amelioration by antioxidants," Neurochemical Research, vol. 35, no. 7, pp. 1017-1028, 2010.

[17] J. Krechniak and I. Inkielewicz, "Correlations between fluoride concentrations and free radical parameters in soft tissues of rats," Fluoride, vol. 38, no. 4, pp. 293-296, 2005.
[18] D. A. Butterfield, "Oxidative stress in neurodegenerative disorders," Antioxidants and Redox Signaling, vol. 8, no. 11-12, pp. 1971-1973, 2006.

[19] D. F. Donnelly and J. L. Carroll, "Mitochondrial function and carotid body transduction," High Altitude Medicine and Biology, vol. 6, no. 2, pp. 121-132, 2005.

[20] J. D. Lambeth, "NOX enzymes and the biology of reactive oxygen," Nature Reviews Immunology, vol. 4, no. 3, pp. 181$189,2004$.

[21] M. Geiszt and T. L. Leto, "The Nox family of NAD(P)H oxidases: host defense and beyond," Journal of Biological Chemistry, vol. 279, no. 50, pp. 51715-51718, 2004.

[22] K. D. Barron, "The microglial cell. A historical review," Journal of the Neurological Sciences, vol. 134, supplement 1, pp. 57-68, 1995.

[23] G. W. Kreutzberg, "Microglia: a sensor for pathological events in the CNS," Trends in Neurosciences, vol. 19, no. 8, pp. 312318, 1996.

[24] C. A. Colton and D. L. Gilbert, "Production of superoxide anions by a CNS macrophage, the microglia," FEBS Letters, vol. 223, no. 2, pp. 284-288, 1987.

[25] R. B. Banati, J. Gehrmann, P. Schubert, and G. W. Kreutzberg, "Cytotoxicity of microglia," Glia, vol. 7, no. 1, pp. 111-118, 1993.

[26] J. Gehrmann, Y. Matsumoto, and G. W. Kreutzberg, "Microglia: intrinsic immuneffector cell of the brain," Brain Research Reviews, vol. 20, no. 3, pp. 269-287, 1995.

[27] S. H. Choi, Y. L. Da, U. K. Seung, and K. J. Byung, "Thrombininduced oxidative stress contributes to the death of hippocampal neurons in vivo: role of microglial NADPH oxidase," Journal of Neuroscience, vol. 25, no. 16, pp. 4082-4090, 2005.

[28] M. M. Bradford, "A rapid and sensitive method for the quantitation of microgram quantities of protein utilizing the principle of protein dye binding," Analytical Biochemistry, vol. 72, no. 1-2, pp. 248-254, 1976.

[29] G. Rothe and G. Valet, "Flow cytometric analysis of respiratory burst activity in phagocytes with hydroethidine and 2',7'dichlorofluorescin," Journal of Leukocyte Biology, vol. 47, no. 5, pp. 440-448, 1990.

[30] P. A. Bush, N. E. Gonzalez, J. M. Griscavage, and L. J. Ignarro, "Nitric oxide synthase from cerebellum catalyzes the formation of equimolar quantities of nitric oxide and citrulline from L-arginine," Biochemical and Biophysical Research Communications, vol. 185, no. 3, pp. 960-966, 1992.

[31] J. E. Le Belle, N. M. Orozco, A. A. Paucar et al., "Proliferative neural stem cells have high endogenous ROS levels that regulate self-renewal and neurogenesis in a PI3K/Akt-dependant manner," Cell Stem Cell, vol. 8, no. 1, pp. 59-71, 2011.

[32] Q. Li and J. F. Engelhardt, "Interleukin- $1 \beta$ induction of $N F \kappa B$ is partially regulated by $\mathrm{H} 2 \mathrm{O} 2$-mediated activation of $\mathrm{NF} \kappa \mathrm{B}-$ inducing kinase," Journal of Biological Chemistry, vol. 281, no. 3, pp. 1495-1505, 2006.

[33] P. Jenner, "Oxidative mechanisms in nigral cell death in Parkinson's disease," Movement Disorders, vol. 13, supplement 1, pp. 24-34, 1998.

[34] H. Bouaziz, F. Croute, T. Boudawara, J. P. Soleilhavoup, and N. Zeghal, "Oxidative stress induced by fluoride in adult mice and their suckling pups," Experimental and Toxicologic Pathology, vol. 58, no. 5, pp. 339-349, 2007.

[35] Y. M. Shivarajashankara, A. R. Shivashankara, S. Hanumanth Rao, and P. Gopalakrishna Bhat, "Oxidative stress in children with endemic skeletal fluorosis," Fluoride, vol. 34, no. 2, pp. 103-107, 2001. 
[36] R. Rzeuski, D. Chlubek, and Z. Machoy, "Interactions between fluoride and biological free radical reactions," Fluoride, vol. 31, no. 1, pp. 43-45, 1998.

[37] Y. M. Shivarajashankara, A. R. Shivashankara, P. Gopalakrishna Bhat, and S. Hanumanth Rao, "Effect of fluoride intoxication on lipid peroxidation and antioxidant systems in rats," Fluoride, vol. 34, no. 2, pp. 108-113, 2001.

[38] D. Saralakumari and P. R. Rao, "Red blood cell glucose metabolism in human chronic fluoride toxicity," Bulletin of Environmental Contamination and Toxicology, vol. 47, no. 6, pp. 834-839, 1991.

[39] B. Liu and J. S. Hong, "Role of microglia in inflammationmediated neurodegenerative diseases: mechanisms and strategies for therapeutic intervention," Journal of Pharmacology and Experimental Therapeutics, vol. 304, no. 1, pp. 1-7, 2003.

[40] K. M. Boje and P. K. Arora, "Microglial-produced nitric oxide and reactive nitrogen oxides mediate neuronal cell death," Brain Research, vol. 587, no. 2, pp. 250-256, 1992.

[41] C. C. Chao, S. Hu, T. W. Molitor, E. G. Shaskan, and P. K. Peterson, "Activated microglia mediate neuronal cell injury via a nitric oxide mechanism," Journal of Immunology, vol. 149, no. 8, pp. 2736-2741, 1992.

[42] R. Dringen, "Oxidative and antioxidative potential of brain microglial cells," Antioxidants and Redox Signaling, vol. 7, no. 9-10, pp. 1223-1233, 2005.

[43] A. Vezzani, R. Monhemius, P. Tutka, R. Milani, and R. Samanin, "Functional activation of somatostatin- and neuropeptide Y-containing neurons in the entorhinal cortex of chronically epileptic rats," Neuroscience, vol. 75, no. 2, pp. 551557, 1996.

[44] N. Stence, M. Waite, and M. E. Dailey, "Dynamics of microglial activation: a confocal time-lapse analysis in hippocampal slices," Glia, vol. 33, no. 3, pp. 256-266, 2001.

[45] R. H. Hoek, S. R. Ruuls, C. A. Murphy et al., "Down-regulation of the macrophage lineage through interaction with OX2 (CD200)," Science, vol. 290, no. 5497, pp. 1768-1771, 2000.

[46] S. Boillée and D. W. Cleveland, "Revisiting oxidative damage in ALS: microglia, Nox, and mutant SOD1," Journal of Clinical Investigation, vol. 118, no. 2, pp. 474-478, 2008.

[47] M. Patel, Q. Y. Li, L. Y. Chang, J. Crapo, and L. P. Liang, "Activation of NADPH oxidase and extracellular superoxide production in seizure-induced hippocampal damage," Journal of Neurochemistry, vol. 92, no. 1, pp. 123-131, 2005.

[48] C. S. Yang, H. M. Lee, J. Y. Lee et al., "Reactive oxygen species and p47phox activation are essential for the Mycobacterium tuberculosis-induced pro-inflammatory response in murine microglia," Journal of Neuroinflammation, vol. 4, p. 27, 2007.

[49] N. A. Christie, A. S. Slutsky, B. A. Freeman, and A. K. Tanswell, "A critical role for thiol, but not ATP, depletion in 95\% O2mediated injury of preterm pneumocytes in vitro," Archives of Biochemistry and Biophysics, vol. 313, no. 1, pp. 131-138, 1994.

[50] Z. Gregus, T. Fekete, E. Halaszi, and C. D. Klaassen, "Lipoic acid impairs glycine conjugation of benzoic acid and renal excretion of benzoylglycine," Drug Metabolism and Disposition, vol. 24, no. 6, pp. 682-688, 1996.

[51] A. Bal-Price and G. C. Brown, "Inflammatory neurodegeneration mediated by nitric oxide from activated glia-inhibiting neuronal respiration, causing glutamate release and excitotoxicity," Journal of Neuroscience, vol. 21, no. 17, pp. 6480-6491, 2001.

[52] G. C. Brown, "Mechanisms of inflammatory neurodegeneration: INOS and NADPH oxidase," Biochemical Society Transactions, vol. 35, no. 5, pp. 1119-1121, 2007.
[53] H. M. Gibbons and M. Dragunow, "Microglia induce neural cell death via a proximity-dependent mechanism involving nitric oxide," Brain Research, vol. 1084, no. 1, pp. 1-15, 2006.

[54] C. Nathan and Q. W. Xie, "Nitric oxide synthases: roles, tolls, and controls," Cell, vol. 78, no. 6, pp. 915-918, 1994.

[55] C. Nathan and Q. W. Xie, "Regulation of biosynthesis of nitric oxide," Journal of Biological Chemistry, vol. 269, no. 19, pp. 13725-13728, 1994.

[56] N. Shibata and M. Kobayashi, "The role for oxidative stress in neurodegenerative diseases," Brain and Nerve, vol. 60, no. 2, pp. 157-170, 2008. 


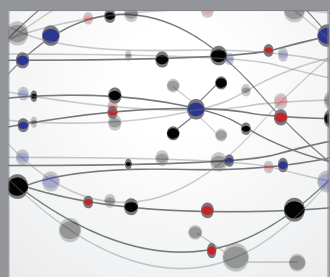

The Scientific World Journal
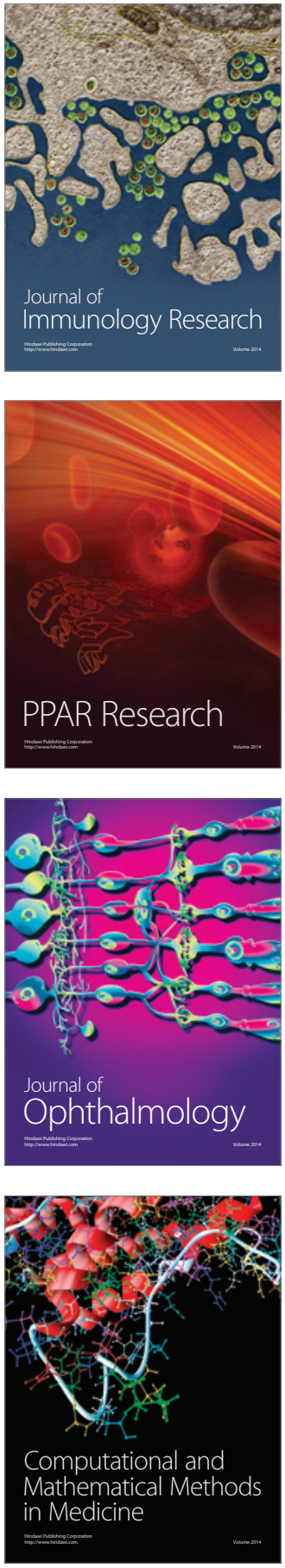

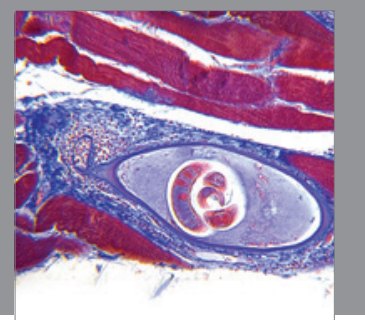

Gastroenterology

Research and Practice
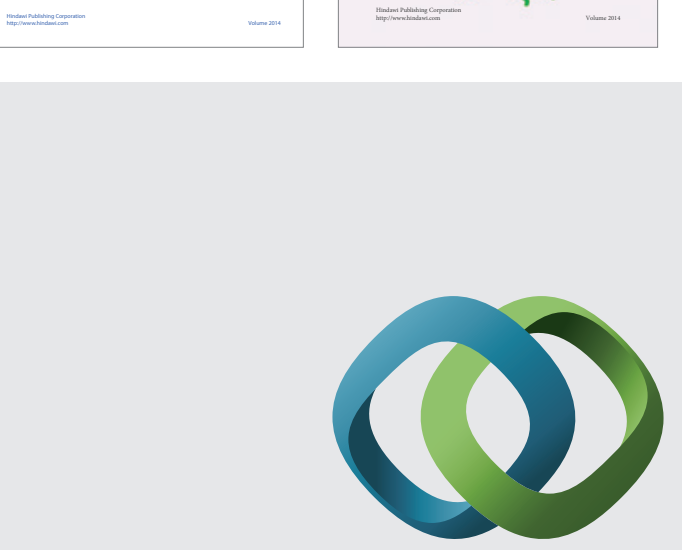

\section{Hindawi}

Submit your manuscripts at

http://www.hindawi.com
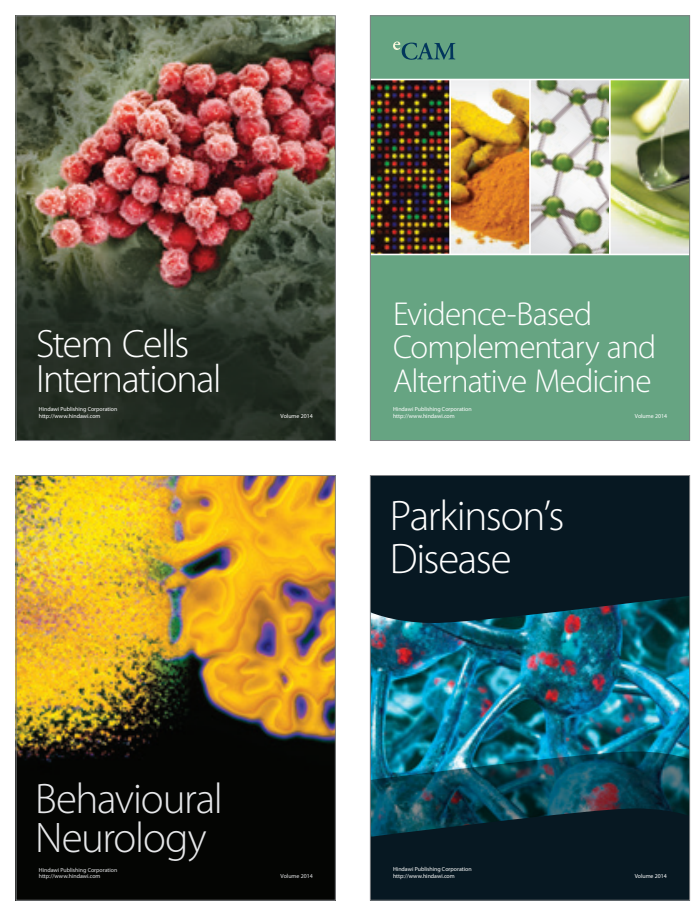

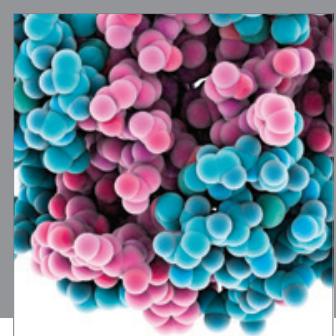

Journal of
Diabetes Research

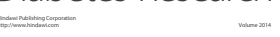

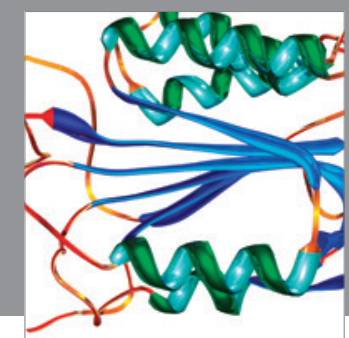

Disease Markers
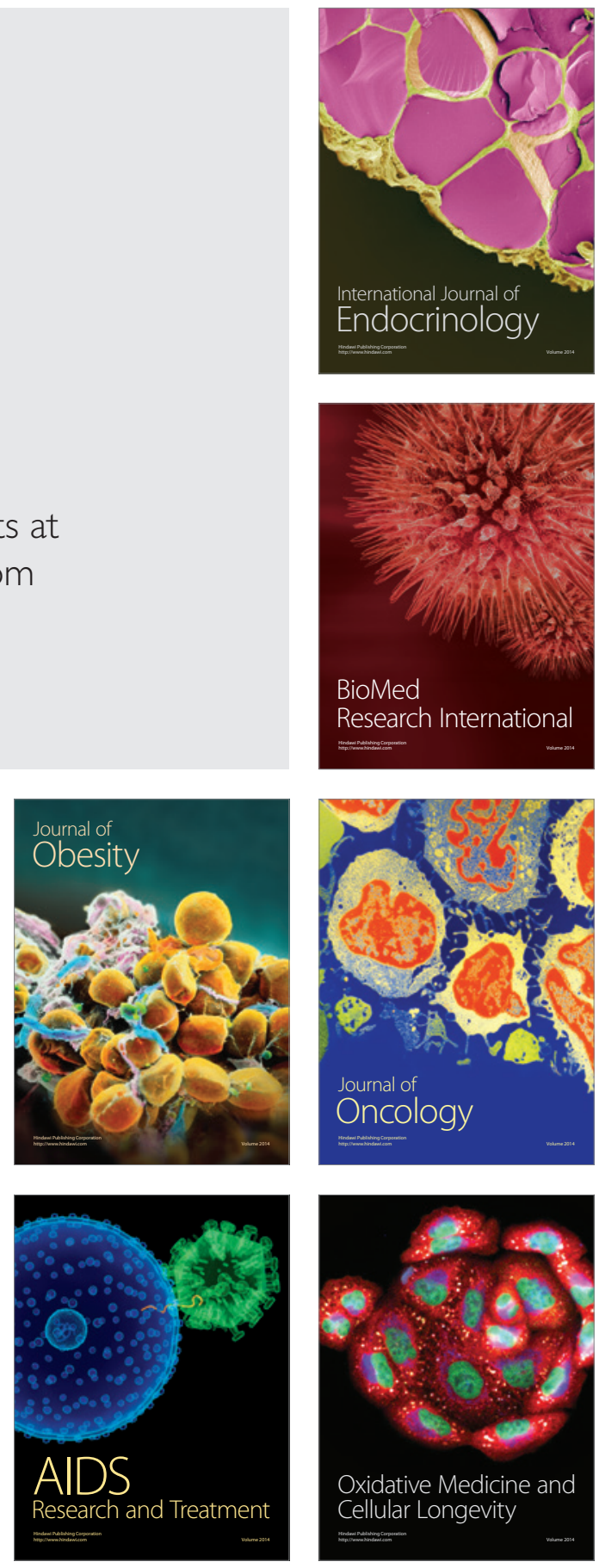